\section{Irrigation Frequency Affects Zoysiagrass Rooting and Plant Water Status}

\author{
Y.L. Qian' ${ }^{1}$ and J.D. Fry ${ }^{2}$ \\ Department of Horticulture, Forestry, and Recreation Resources, Kansas \\ State University, Manhattan, KS 66506-5506
}

Additional index words. leaf water potential, osmotic adjustment, soil moisture content, Zoysia japonica

\begin{abstract}
Meyer' zoysiagrass (Zoysia japonica Steud.) was established on a silt loam soil in $27-\mathrm{cm}$-diameter $\times 92-\mathrm{cm}$-deep containers in a greenhouse to investigate the influence of irrigation frequency on turfgrass rooting and drought tolerance. Turf was irrigated daily or at the onset of leaf rolling with a water volume equal to the cumulative evapotranspiration of well-watered turf in small weighing lysimeters. After $>90$ days of irrigation treatments, a dry-down was imposed during which no additional water was applied for 55 days. A recovery period followed during which time turf was watered to maintain soil matric potential at greater than $-30 \mathrm{kPa}$. Compared to turf irrigated daily, that watered at the onset of leaf rolling exhibited 1) $32 \%$ to $36 \%$ lower leaf water potential and $14 \%$ to $22 \%$ lower osmotic potential before the onset of drought; 2) $13 \%$ higher leaf water potential $\approx \mathbf{4 0}$ days into dry-down; 3 ) more extensive rooting at 55 - and 75 -cm soil depths as indicated by $11 \%$ to $19 \%$ lower volumetric soil moisture content at the end of dry-down; 4) $25 \%$ to $40 \%$ lower shoot growth rate during irrigation and $13 \%$ to $33 \%$ higher shoot growth rate during dry-down; and 5) higher quality ratings during dry-down and recovery. Thus, deep, infrequent irrigation better prepares zoysiagrass for an oncoming drought than light, frequent irrigation.
\end{abstract}

Recommendations for turfgrass irrigation traditionally have been to water deeply and infrequently to encourage deep rooting and create a drought-tolerant plant (Beard, 1973). In a series of experiments (Bennett and Doss, 1960; Doss et al., 1960), rooting of warm- and cool-season forage grasses was enhanced by allowing soil in the upper $60 \mathrm{~cm}$ to dry to $15 \%$ vs. $70 \%$ available soil water content. In a California field study (Madison and Hagan, 1962), irrigating every 20 days enhanced Kentucky bluegrass (Poa pratensis L.) rooting compared to irrigation three times weekly. However, St. Augustinegrass [Stenotaphrum secundatum (Walt.) Kuntze] rooting was not affected by irrigating every 2,3,4, or 6 days with 3.8 or $6.4 \mathrm{~mm}$ water/day (Peacock and Dudeck, 1985).

Work has been done in crops other than turf to investigate irrigation frequency effects on physiological response to a subsequent drought. Cotton (Gossypium hirsutum L.) irrigated every 8 days maintained leaf turgor and leaf blade elongation longer and was slower to close stomata during a subsequent drought

Received for publication 24 July 1995. Accepted for publication 29 Dec. 1995. Kansas Agricultural Expt. Station contribution no. 96-16-J. Research supported in part by the City of Wichita Public Works Dept., Kansas Golf Course Superintendent's Association, Heart of America Golf Course Superintendent's Association, and the Kansas Turfgrass Foundation. The cost of publishing this paper was defrayed in part by the payment of page charges. Under postal regulations, this paper therefore must be hereby marked advertisement solely to indicate this fact. ${ }^{1}$ Graduate Research Assistant.

${ }^{2}$ Associate Professor. compared to plants irrigated every 1 or 4 days (Cutler and Rains, 1977). Spring wheat (Triticum aestivum L.) irrigated every 12 days exhibited a slower reduction in leaf water potential $\left(\psi_{\mathrm{L}}\right)$ during dry-down than plants watered on a 4-day interval (Proffitt et al., 1985). To our knowledge, no research has been done with turfgrass to evaluate effects of irrigation frequency on physiological response to a subsequent drought.

'Meyer' zoysiagrass is used widely throughout the transition zone, a suboptimal area between cool and warm climates where both cool- and warm-season turfgrass can be grown. Like turfgrass on many sites, zoysiagrass is often subject to routine, fremore, occurrence of an extended period of wet weather followed by a severe drought is not uncommon in the midwestern United States. To our knowledge, no information is available on effects that frequent irrigation or extended periods of rainfall may have on zoysiagrass response to a subsequent drought. In this study, 'Meyer' zoysiagrass was evaluated to determine effects of irrigation frequency on rooting and plant water status.

\section{Materials and Methods}

Study I. Research was conducted in the greenhouse from 14 Sept. 1993 to 5 Apr. 1994. 'Meyer' zoysiagrass was sodded on a loam soil retained in 12 polyvinyl chloride cylinders measuring $27 \mathrm{~cm}$ in diameter $\times 92 \mathrm{~cm}$ deep with a volume of 52 liters. A fiberglass bottom perforated with five 2.5 -cm-diameter holes was fastened to the base of each cylinder. A 3quent (4 to 7 days weekly) irrigation. Further- cm-deep pea gravel layer was placed at the bottom of each column to prevent soil loss through holes. A field loam soil (23\% sand, $48 \%$ silt, $29 \%$ clay, $2.9 \%$ organic matter, $\mathrm{pH}$ 6.5) was packed firmly to achieve a bulk density $\approx 1.5 \mathrm{~g} \cdot \mathrm{cm}^{-3}$ in each container. A $2-\mathrm{cm}$ void remained between the container top and soil surface. Average air temperature was 21 to $27 \mathrm{C}$. Three high-intensity sodium lamps were placed $105 \mathrm{~cm}$ above the containers to supplement natural light with 100 to 120 $\mu \mathrm{mol} \cdot \mathrm{m}^{-2} \cdot \mathrm{s}^{-1}$ photosynthetically active radiation (PAR) between 0600 and $2000 \mathrm{HR}$.

Before irrigation treatments began, grass in all containers was watered daily until roots reached a $20-\mathrm{cm}$ depth, as determined by sodding turf on a similar soil medium in an adjacent container, and periodically pulling it up at one edge to estimate rooting depth visually.

A $20 \mathrm{~N}-4 \mathrm{P}-17 \mathrm{~K}$ soluble fertilizer was applied once to provide $4.9 \mathrm{~g} \mathrm{~N} / \mathrm{m}^{2}$. After roots had reached the $20-\mathrm{cm}$ depth, turf in six of the containers was watered daily [i.e., frequently watered $(\mathrm{FW})]$ and that in the remaining six containers was watered at the first indication of leaf rolling [i.e., infrequently watered(IW)]. Irrigation was applied to equal $100 \%$ cumulative daily evapotranspiration, which was determined by weighing three mini-lysimeters (25 cm in diameter, $24 \mathrm{~cm}$ deep) containing zoysiagrass maintained under the same ambient conditions and adjacent to the 12 containers. Soil matric potential in lysimeters was maintained at about $-30 \mathrm{kPa}$ by watering daily. All containers received the same amount of water; only application frequency varied. Irrigation treatments continued for 92 days. During this period, IW turf received four irrigation applications (every 19 to 26 days), ranging from 78 to $124 \mathrm{~mm}$ each; FW turf received 92 applications, ranging from 2.4 to $6.3 \mathrm{~mm}$ each. Throughout the study, turf was mowed weekly at $5 \mathrm{~cm}$ with clippings removed. Visual turf quality was rated weekly on a 0 to 9 scale, where $0=$ brown, thin, dead turf; $9=$ dense, uniform, bright-green, and nonstressed turf; and $6=$ acceptable quality. Weekly shoot growth rate was determined by measuring canopy height with a ruler and calculating the difference between the canopy height and mowing height.

After 92 days of irrigation treatments, turf in all containers was subjected to a 55-day drydown during which no water was applied. Weekly mowing continued. Data were collected on turf quality (as previously described); soil water content at 15-, 35-, 55-, and 75-cm depths; $\psi_{\mathrm{L}}$; leaf osmotic potential $\left(\psi_{\mathrm{S}}\right)$; and leaf pressure potential $\left(\psi_{\mathrm{P}}\right)$.

The relatively small area of turf in each container did not allow cores to be removed and root masses to be determined at regular intervals. Rather, we used changes in soil water content at 15-, 35-, 55-, and 75-cm depths as indicators of root activity. Other researchers have concluded that soil water content provided a good indicator of root distribution or similarly used soil water extraction to determine differences in rooting among grasses (Bennett and Doss, 1960; Doss et al., 1960; Sheffer et al., 1987). 
To determine volumetric soil water content (VSWC) by time-domain reflectometry (TDR), holes to accommodate TDR probes were drilled in the sides of the PVC containers at 15-, 35-, 55-, and 75-cm depths 45 days into dry-down. Two 23-cm-long stainless steel probes were inserted horizontally at each depth. Clear silicone glue was used to seal the holes and anchor the probes. Soil water content was measured with an IRAMS soil moisture analyzer (Soil Moisture Equipment Corp., Santa Barbara, Calif.) 47 and 53 days into the stress period. Leaf water potential and $\psi_{\mathrm{s}}$ were measured using precalibrated thermocouple psychrometers (model 75-1AC; J.R.D. Merrill Specialty Equipment Corp., Logan, Utah) and a dewpoint microvoltmeter (model HR-33T; Wescor, Logan, Utah) as described by Kirkham (1985). Between 1100 and $1200 \mathrm{HR}$, two recently, fully expanded leaf blades from each container were excised at the collar and placed in a psychrometer chamber. The leaves were equilibrated at $26 \mathrm{C}$ for $3.5 \mathrm{~h}$ before $\psi_{\mathrm{L}}$ was measured in the psychrometric mode with a cooling time of $30 \mathrm{sec}$. To determine $\psi_{\mathrm{s}}$, the thermocouple psychrometer chamber containing leaf tissue was separated from the thermocouple, corked, and frozen at $-15 \mathrm{C}$ for $24 \mathrm{~h}$. Chambers then were removed from the freezer, thawed at $25 \mathrm{C}$ for $1 \mathrm{~h}$, uncorked, and quickly returned to the thermocouple. After equilibration for $3.5 \mathrm{~h}, \psi_{\mathrm{S}}$ was measured as described for $\psi_{\mathrm{L}}$ measurement. Leaf pressure potential was calculated by subtracting $\psi_{\mathrm{S}}$ from $\psi_{\mathrm{L}}$. When the calculated $\psi_{\mathrm{P}}$ was $<0$, it was adjusted to 0 .

Turf was rewatered 55 days into the stress period. Turf quality was rated at 7,10 , and 14 days after rewatering.

Study II. A second, similar greenhouse study was conducted from 23 Sept. 1994 to 1 May 1995. Materials and methods were the same as in Study I with the following exceptions:

1) Irrigation treatments continued for 107 days before dry-down began, and IW turf received five irrigations (every 16 to 27 days with 72 to $120 \mathrm{~mm}$ water applied each time); FW turf received 107 irrigations with a mean of $4.0 \mathrm{~mm}$ water applied each time.

2) The day after irrigation treatments ceased, leaf osmotic potential at full turgor $\left(\psi_{\mathrm{s}}{ }^{100}\right)$ was measured to determine if irrigation regime affected osmotic adjustment.

3) The dewpoint rather than the psychrometric mode was used to measure $\psi_{\mathrm{L}}$ and $\psi_{\mathrm{S}}$ in thermocouple psychrometers.

4) The TDR probes were inserted horizontally before dry-down, and soil water content at 15-, 35-, 55-, and 75-cm depths was measured weekly.

5) Weekly shoot growth rate was measured during dry-down as done during the irrigation period in Study I.

To measure $\psi_{\mathrm{s}}{ }^{100}, 10$ fully expanded leaf blades were excised at the collar and immediately immersed in distilled water for $8 \mathrm{~h}$ under fluorescent light $\left(\mathrm{PAR}=15 \mu \mathrm{mol} \cdot \mathrm{m}^{-2} \cdot \mathrm{s}^{-1}\right)$ to bring them to full hydration. Leaves then were blotted dry, placed into siliconized microcentrifuge tubes, and set in a $-15 \mathrm{C}$ freezer for
24 h. $\psi_{\mathrm{S}}{ }^{100}$ was measured on sap expressed from the leaves with a laboratory press (Fred S. Carver, Wabash, Ind.) after a 30-min thaw. A $10-\mu \mathrm{l}$ aliquot of the expressed sap was injected onto a SS-033 Sample Disc (Wescor) that was placed in the sampling chamber of a model 5500 vapor pressure osmometer (Wescor).

Data analysis. In both experiments, containers were arranged in a completely randomized block design with two treatments and six replications. Analysis of variance indicated a treatment $\times$ study interaction; therefore, data from each study were analyzed separately. Data for turf quality and growth rate were analyzed over all dates using repeated measures analysis (Milliken and Johnson, 1984). Data on $\psi_{\mathrm{s}}{ }^{100}$ collected in Study II were subjected to a Student $t$ test to determine differences between irrigation treatments. Because drought conditions changed over time, $\psi_{\mathrm{L}}, \psi_{\mathrm{S}}$, $\psi_{\mathrm{P}}$, and soil water content were analyzed by individual dates to test for differences between FW and IW treatments.

\section{Results and Discussion}

\section{Irrigation period}

Turf quality and shoot growth. Zoysiagrass receiving FW and IW treatments exhibited good quality in both studies (Table 1). Likewise, Peacock and Dudeck (1984) reported that St. Augustinegrass turf quality was not affected by irrigating every $2,3,4$, or 6 days with an amount of water derived from evapotranspiration estimates. Shoot growth rates of FW zoysiagrass were $25 \%$ and $41 \%$ higher than those of IW zoysiagrass in Study I and Study II, respectively (Table 1). Biran et al. (1981) reported similar findings, in that delaying irrigation until the onset of wilting reduced shoot growth of 11 turfgrass species by up to $35 \%$ in the field. Faster growth often results in higher yields of food crops or forage grasses (Doss et al., 1962), but is undesirable in turfgrass, because more frequent mowing is required. Rapid growth leading to more clippings also depletes turfgrass of carbohydrate reserves that may be needed during periods of stress (Smith, 1972).

Table 1. Turf quality and shoot growth of zoysiagrass irrigated daily [frequent watering $(\mathrm{FW})$ ] or at the onset of leaf rolling [infrequent watering (IW)] and osmotic potential at full turgor $\left(\psi_{\mathrm{s}}^{100}\right)$ before dry-down.

\begin{tabular}{|c|c|c|c|c|c|c|}
\hline \multirow[b]{2}{*}{ Treatment } & \multicolumn{3}{|c|}{ Turf quality $^{2}$} & \multicolumn{2}{|c|}{ Shoot growth $\left(\mathrm{mm} \cdot \mathrm{day}^{-1}\right)$} & \multirow[b]{2}{*}{$\begin{array}{c}\psi_{\mathrm{s}}{ }^{100} \\
(\mathrm{MPa})\end{array}$} \\
\hline & $\begin{array}{l}\text { During } \\
\text { irrigation }\end{array}$ & $\begin{array}{c}\text { During } \\
\text { dry-down }\end{array}$ & $\begin{array}{l}\text { After } \\
\text { recovery }\end{array}$ & $\begin{array}{l}\text { During } \\
\text { irrigation }\end{array}$ & $\begin{array}{c}\text { During } \\
\text { dry-down }\end{array}$ & \\
\hline \multicolumn{7}{|l|}{ Study I } \\
\hline FW & $8.9 \mathrm{a}^{\mathrm{x}}$ & $6.2 \mathrm{~b}$ & $6.6 \mathrm{~b}$ & $7.1 \mathrm{a}$ & --- & --- \\
\hline IW & $8.8 \mathrm{a}$ & $7.6 \mathrm{a}$ & $8.5 \mathrm{a}$ & $5.7 \mathrm{~b}$ & --- & --- \\
\hline \multicolumn{7}{|l|}{ Study II } \\
\hline FW & $8.8 \mathrm{a}$ & $6.4 \mathrm{~b}$ & $7.0 \mathrm{~b}$ & $6.9 \mathrm{a}$ & $2.6 \mathrm{~b}$ & $-1.22 \mathrm{a}$ \\
\hline IW & $8.8 \mathrm{a}$ & $7.3 \mathrm{a}$ & $8.3 \mathrm{a}$ & $4.9 \mathrm{~b}$ & $3.4 \mathrm{a}$ & $-1.52 b$ \\
\hline
\end{tabular}

${ }^{2}$ Turf quality was rated visually on a 0 to 9 scale where $0=$ brown, thin turf, and $9=$ dense, uniform, and nonstressed turf. Means during irrigation are from 13 and 15 weekly ratings in Studies I and II, respectively. Means during dry-down are from 8 weekly ratings. Turf quality after recovery was rated 2 weeks after rewatering.

${ }^{y}$ Shoot growth was measured weekly, and data were converted to mean daily growth. Means during irrigation represent 13 and 15 weekly measurements in Studies I and II, respectively. Means during drydown are from 8 weekly measurements.

${ }^{x}$ Mean separation in columns within each study at $P<0.05$.
Osmotic adjustment. At the end of the irrigation period in Study II, $\psi_{\mathrm{S}}{ }^{100}$ in leaves of IW zoysiagrass was $0.30 \mathrm{MPa}$ lower than that turf (Table 1). Hence, an osmotic adzoysiagrass.

\section{Dry-down period}

Soil water extraction. Forty-seven days into dry-down in Study I, VSWCs were 17\% zoysiagrass (data not shown). VSWC at a 75$\mathrm{cm}$ depth was $19 \%$ lower under IW turf after days of dry-down.

until $\approx 30$ days into dry-down in Study II (Fig. 1). At 30 days into dry-down, VSWC at $75 \mathrm{~cm}$ was $9 \%$ to $11 \%$ lower under IW than under FW Fifty-three days into dry-down, in the root zone under IW turf indicated that roots were present and extracting water. In a field study in Israel (Mantell, 1966), kikuyusubjected to irrigation intervals ranging from 7 to 30 days. Grass irrigated infrequently extracted proportionately more water deeper in soil than turf irrigated frequently.

FW zoysiagrass, $\psi_{\mathrm{L}}$ values of IW turf were $36 \%$ to $40 \%$ lower 1 to 4 days after irrigation ceased in Study I, and 32\% lower 3 days after irrigation ceased in Study II (Fig. 2). The $\psi_{\mathrm{L}}$ higher than those of FW turf 31 to 41 days into dry-down in Study I and $11 \%$ to $13 \%$ higher than those of FW turf 30 to 40 days into dryin Study II (Fig. 2). $33 \%$ lower than those of FW turf in Study I and $14 \%$ lower than those of FW turf in Study II, reflecting osmotic adjustment during the irriFW turf compared to IW turf, likely because FW zoysiagrass leaves were more dehydrated than leaves of IW turf. $55-\mathrm{cm}$ depth under IW compared to FW lower than that under FW turf. Drier soil deep

1 to 4 days after irrigation ceased were $22 \%$ to stress period in Study I, $\psi_{s}$ was $12 \%$ lower in 


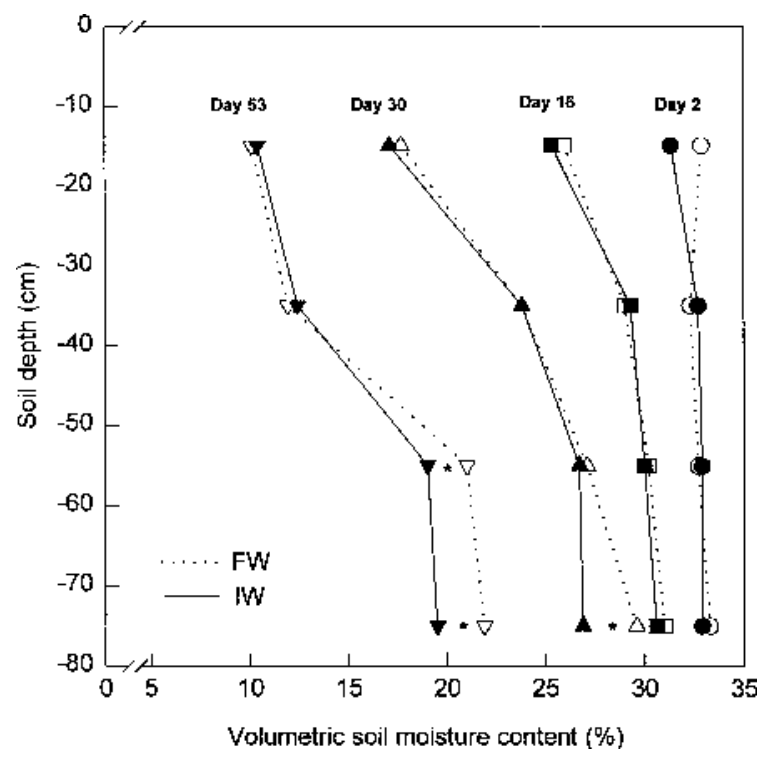

Fig. 1. Volumetric soil water content at four soil depths 2, 16, 30, and 53 days after frequent (FW) and infrequent (IW) irrigation treatments ceased, Study II. Asterisks denote a significant difference between irrigation treatments $(P<0.05)$. Data are means of six replicates.

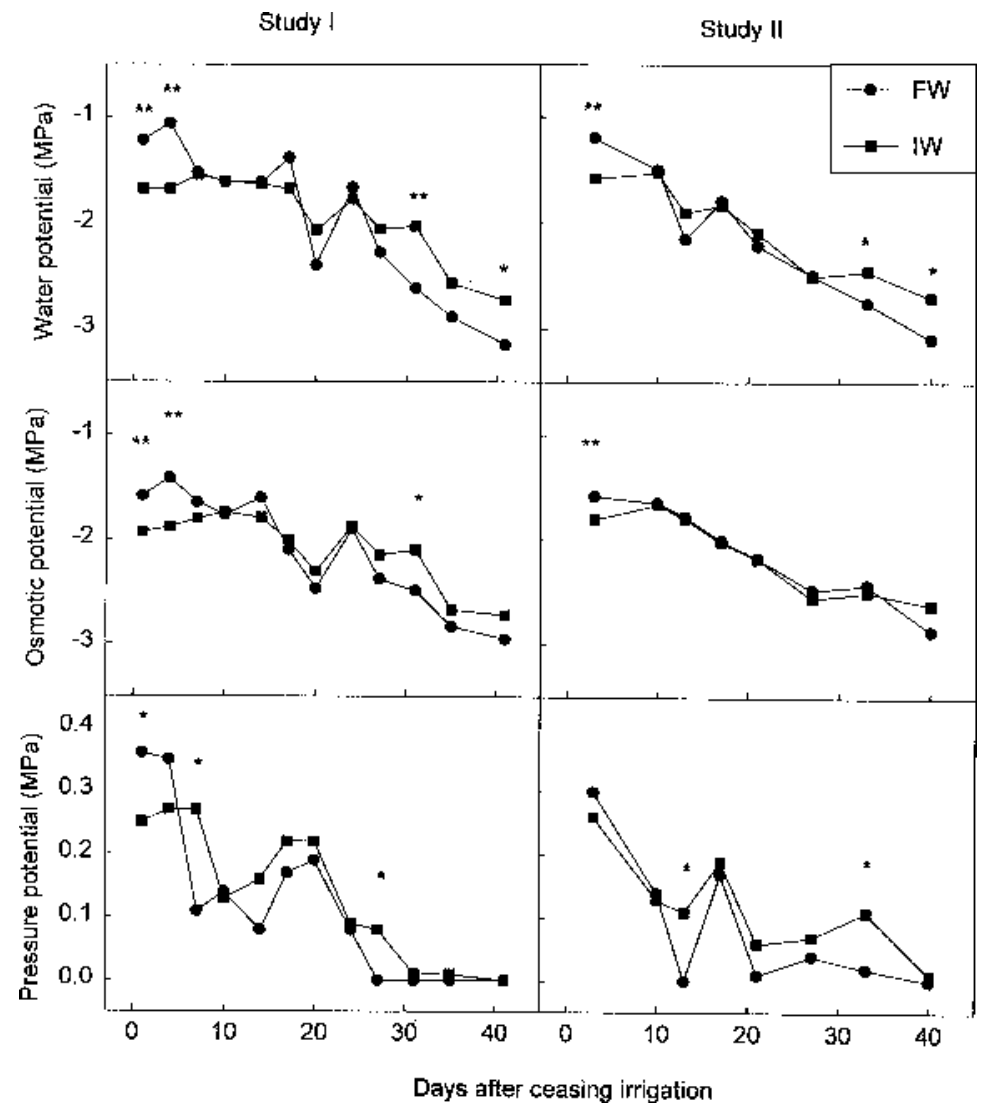

Fig. 2. Influence of frequent (FW) and infrequent (IW) irrigation treatments on leaf water potential, osmotic potential, and pressure potential during a subsequent dry-down in Studies I and II. *, **Treatments significantly different at $P<0.10$ and 0.05 , respectively. Data are means of six replicates.

Pressure potential was $0.11 \mathrm{MPa}$ higher in FW turf than IW turf on the first day into drydown in Study I. However, IW turf exhibited higher $\psi_{\mathrm{P}}$ on at least one occasion between 25 and 40 days into dry-down in both studies (Fig. 2).

Turf quality and shoot growth. Quality of FW zoysiagrass declined more rapidly than quality of IW turf during dry-down $(P<0.05)$ (data not shown). Quality of IW turf was 1.4 units higher than that of FW turf in Study I and 1.1 units higher in Study II (Table 1). Shoot growth rate of FW turf was $24 \%$ lower than that of IW turf during dry-down (Table 1), which likely was due to higher leaf turgor potential (Fig. 2).

When watered at the onset of leaf rolling, zoysiagrass has the capacity to adjust osmoti- cally and extract more water deep in the soil profile. Our results parallel those of Proffitt et al. (1985), who evaluated the drought response of spring wheat. In that study, plants were irrigated every 4 or 12 days for 3 months based upon ET from a well-watered lysimeter situated nearby, and then irrigation ceased. After 18 days with no irrigation, $\psi_{\mathrm{L}}$ in wheat watered every 4 days was $\approx 0.3 \mathrm{MPa}$ lower than that of plants watered on a 12-day interval. Conversely, Devitt et al. (1993) observed that midday $\psi_{\mathrm{L}}$ of bermudagrass [Cynodon dactylon (L.)Pers] was fairly constant for 60 days during a 95-day dry-down regardless of whether irrigation with saline water was applied previously one, two, or four times weekly (Devitt et al., 1991). These results suggest that the effect of irrigation frequency on grass response to a subsequent drought may differ with grass species or salinity level of the irrigation water.

We have documented with this work the morphological and physiological benefits that zoysiagrass is afforded by deep, infrequent irrigation. Turf managers that irrigate zoysiagrass on a frequent, routine schedule are limiting the plant's ability to tolerate a potential, subsequent drought. However, zoysiagrass management immediately following an extended period of wet weather should include light, frequent irrigation to accommodate a plant with shallow roots and poor drought tolerance.

\section{Literature Cited}

Beard, J.B. 1973. Turfgrass: Science and culture. Prentice-Hall, Englewood Cliffs, N.J.

Bennett, O.L. and B.D. Doss. 1960. Effect of soil moisture level on root distribution of coolseason species. Agron. J. 52:204-207.

Biran, I., B. Bravdo, I. Bushkin-Harav, and E. Rawitz. 1981. Water consumption and growth rate of 11 turfgrasses as affected by mowing height, irrigation frequency, and soil moisture. Agron. J. 73:85-90.

Cutler, J.M. and D.W. Rains. 1977. Effects of irrigation history on responses to subsequent water stress. Crop Sci. 17:329-335.

Devitt, D.A., D.C. Bowman, and R.L. Morris. 1991. Effects of irrigation frequency, salinity of irrigation water, and soil type on growth and response of bermudagrass. Arid Soil Res. \& Rehabilitation 5:35-46.

Devitt, D.A., D.C. Bowman, and P.J. Schulte. 1993. Response of Cynodon dactylon to prolonged water deficits under saline conditions. Plant \& Soil 148:239-251.

Doss, B.D., D.A. Ashley, and O.L. Bennett. 1960. Effect of soil moisture regime on rooting distribution of warm-season forage species. Agron. J. 52:569-572.

Doss, B.D., O.L. Bennett, D.A. Ashley, and H.A. Weaver. 1962. Soil moisture regime effect on yield and evapotranspiration from warm-season perennial forage species. Agron. J. 54:239242.

Kirkham, M.B. 1985. Techniques for water-use measurements of crop plants. HortScience 20:993-1001.

Madison, J.H. and R.M. Hagan. 1962. Extraction of soil moisture by 'Merion' bluegrass turf, as affected by irrigation frequency, mowing height, and other cultural operations. Agron. J. 54:157160.

Mantell, A. 1966. Effect of irrigation frequency and 
nitrogen fertilization on growth and water use of kikuyugrass turf. Agron. J. 58:559-561.

Milliken, G.A. and D.E. Johnson. 1984. Analysis of messy data. vol. 1. Designed experiments. Wadsworth, Belmont, Calif.

Peacock, C.H. and A.E. Dudeck. 1984. Physiological response of St. Augustinegrass to irrigation scheduling. Agron. J. 76:275-279.
Peacock, C.H. and A.E. Dudeck. 1985. Effect of irrigation interval on St. Augustinegrass rooting. Agron. J. 77:813-815.

Proffitt, A.P.B.,P.R. Berliner, and D.M. Oosterhuis 1985. A comparative study of root distribution and water extraction efficiency by wheat grown under high- and low-frequency irrigation. Agron. J. 77:655-662.
Sheffer, K.M., J.H. Dunn, and D.D. Minner. 1987. Summer drought response and rooting depth of three cool-season turfgrasses. HortScience 22:296-297.

Smith, D. 1972. Carbohydrate reserves of grasses, p. 318-333. In: V.B. Youngner and C.M. Mckell (eds.). The biology and utilization of grasses. Academic, New York. 